\begin{tabular}{|c|l|}
\hline Title & A sensitivity study of the dense shelf water formation in the Okhotsk Sea \\
\hline Author(s) & Sasajima, Y.; Hasumi, H.; Nakamura, T. \\
\hline Citation & Journal of Geophysical Research, 115, C11007 \\
\hline https:/doi.org/LO1029/2009JC005697 \\
\hline Issue Date & 2010-11-10 \\
\hline Doc URL & http://hdl.handle.net/2115/46965 \\
\hline Rights & Copyright 2010 by the American Geophysical Union. \\
\hline Type & article \\
\hline File Information & JGR115_C11007.pdf \\
\hline
\end{tabular}

Instructions for use 


\title{
A sensitivity study of the dense shelf water formation in the Okhotsk Sea
}

\author{
Y. Sasajima, ${ }^{1}$ H. Hasumi, ${ }^{1}$ and T. Nakamura ${ }^{2}$ \\ Received 18 August 2009; revised 27 May 2010; accepted 9 June 2010; published 10 November 2010. \\ [1] Sensitivity of Dense Shelf Water (DSW) formation to tidal mixing around the Kuril \\ Straits, wind stress, and river runoff in the Okhotsk Sea is examined by an ice-ocean \\ coupled model. Horizontal resolution of the model is set to $3-8 \mathrm{~km}$ in the northern \\ Okhotsk Sea for well resolving the coastal polynyas which is believed to be the principal \\ region of DSW formation. The model shows a good performance in terms of sea ice \\ production and the consequent DSW formation. DSW is also found to be formed in the \\ offshore region apart from the coastal polynya. DSW is defined independently for each \\ experiment such that it identifies the water influenced by brine. By introducing such \\ definition the sensitivity of the DSW formation is assessed separately for change of density \\ and that of formation rate. The density of DSW exhibits high sensitivity to all the elements \\ considered herein, while its formation rate is sensitive only to winds. Winds affect the \\ DSW formation rate mainly by influencing that occurs in the offshore region.
}

Citation: Sasajima, Y., H. Hasumi, and T. Nakamura (2010), A sensitivity study of the dense shelf water formation in the Okhotsk Sea, J. Geophys. Res., 115, C11007, doi:10.1029/2009JC005697.

\section{Introduction}

[2] The Okhotsk Sea (Figure 1) is believed to be the formation region for the main source water of North Pacific Intermediate Water (NPIW) [e.g., Talley, 1991; Yasuda, 1997]. The source water of NPIW in the Okhotsk Sea is called Okhotsk Sea Mode Water (OSMW), which is characterized by a minimum of potential vorticity in the density range of 26.6-27.0 $\sigma_{\theta}$ [Yasuda, 1997]. OSMW is formed by the mixing of Dense Shelf Water (DSW), Western Subarctic Water (WSAW) from the North Pacific through the Kuril Straits [Kitani, 1973], and the forerunner of Soya Warm Current Water (SWCW) from the Japan Sea through the Soya Strait [Takizawa, 1982; Watanabe and Wakatsuchi, 1998].

[3] DSW is a relatively cold and fresh water in the Okhotsk Sea and considered the principal ventilating agent for the North Pacific intermediate depths. The density range of DSW is $26.6-27.05 \sigma_{\theta}$, although the definition of the range is slightly different among studies. Itoh et al. [2003] estimated the mixing ratio of the three masses (DSW, WSAW, and SWCW) to form OSMW from an isopycnal climatological data set based on historical observations and suggested that about a half of OSMW is accounted for by DSW.

[4] Kitani [1973] suggested that DSW with density up to $27.02 \sigma_{\theta}$ is formed due to brine rejection through high sea ice formation in the northwestern shelf region located in the

\footnotetext{
${ }^{1}$ Atmosphere and Ocean Research Institute, University of Tokyo, Chiba, Japan.

${ }^{2}$ Institute of Low Temperature Science, Hokkaido University, Hokkaido, Japan.

Copyright 2010 by the American Geophysical Union. 0148-0227/10/2009JC005697
}

north of Sakhalin (see Figure 1). Such high ice production takes place in the coastal polynya along the northwestern coast of the Okhotsk Sea because of strong offshore winds and low air temperature in winter [Alfultis and Martin, 1987; Martin et al., 1998; Ohshima et al., 2003; Shcherbina et al., 2003]. DSW thus formed flows out from the northern shelf region, which is defined as the region shallower than $200 \mathrm{~m}$ deep and to the north of $54^{\circ} \mathrm{N}$ in this study. DSW is transported to the south along the eastern coast of Sakhalin by the East Sakhalin Current [Ohshima et al., 2002; Mizuta et al., 2003] and contributes to the OSMW formation. The volume of DSW in the northern shelf region reaches the maximum in the ice period and decreases after spring due to the flow out. DSW almost vanishes in December [Shcherbina et al., 2004a, 2004b].

[5] The ventilation of the North Pacific intermediate layer and the consequent circulation would be affected by changes in the forcing mechanisms of DSW, such as winds, tidal mixing, and river runoff. For example, the surface wind speed in the ice period exhibits large interannual variability in the northwestern part of the Okhotsk Sea; its standard deviation reaches up to $20 \%$ of its climatological average based on NCEP/NCAR reanalysis [Kalnay et al., 1996]. Nakamura et al. [2006] investigated the effect of tidal mixing in the Kuril Straits on DSW formation with an ice-ocean coupled model. They simulated the basin circulation with and without the tidal mixing, which is represented by a strong vertical diffusivity around the Kuril Islands and suggested that DSW formation is enhanced by the following processes. An upward salinity flux is induced by the tidal mixing effect and increases salinity in the upper layer. This positive anomaly of salinity is transported from the Kuril Islands to the north through the eastern part of the Okhotsk Sea, which is part of 


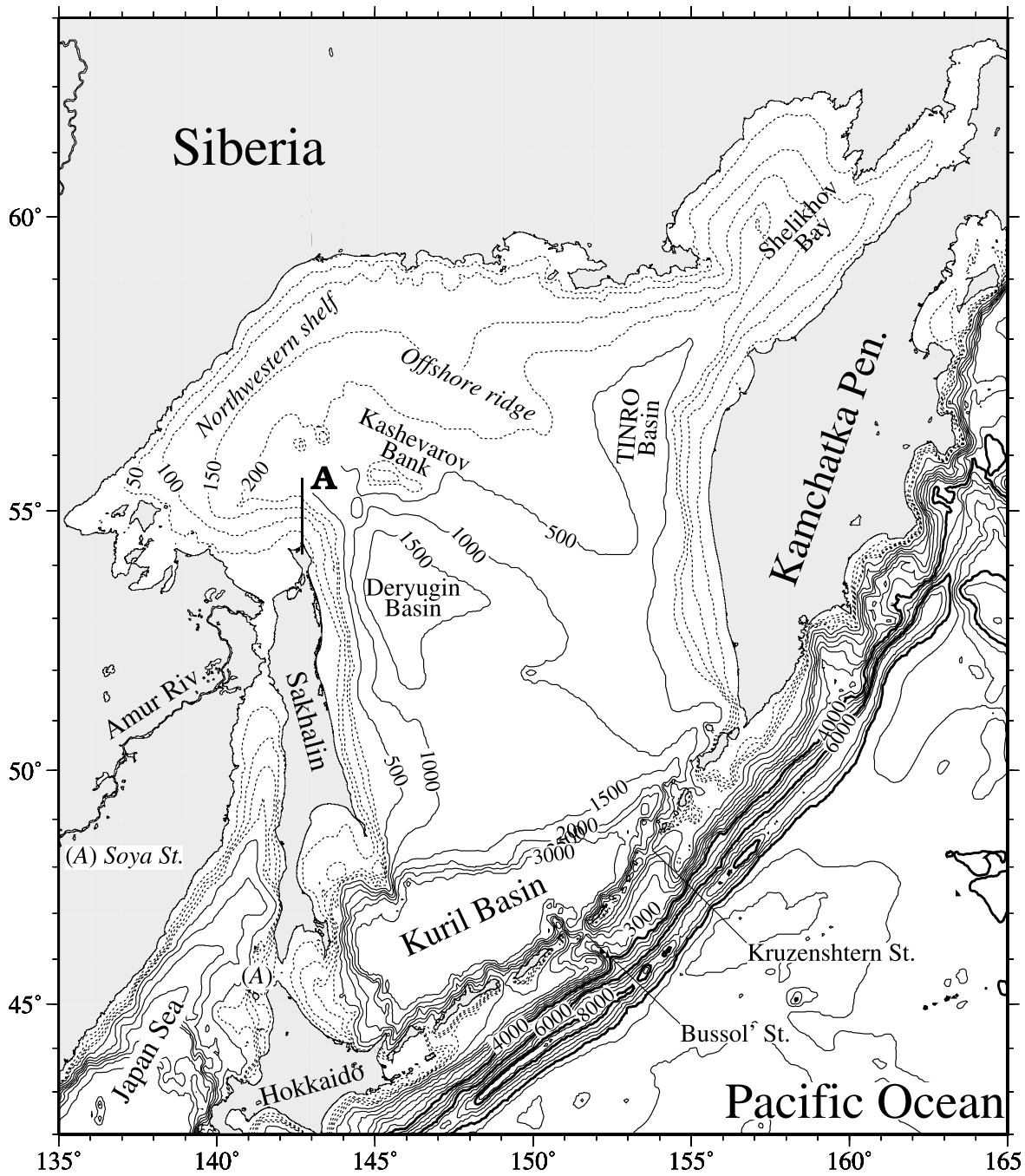

Figure 1. Topographical features of the Okhotsk Sea and surrounding regions. Contours represent the bathymetry $(\mathrm{m})$. A solid line along $142.7^{\circ} \mathrm{E}$ from $54.2^{\circ} \mathrm{N}$ to $55.6^{\circ} \mathrm{N}$ indicates Section A for the DSW transport shown in Table 8.

the basin-scale wind-driven cyclonic circulation [Ohshima et al., 2004]. The transported positive salinity anomaly leads to higher water density at the beginning of winter in the northern shelf region. Matsuda et al. [2009] examined the impact of wind strength on DSW formation under the existence of the strong tidal mixing in the Kuril Straits and showed that stronger wind also enhances the DSW formation. They explained that the wind-driven circulation in the Okhotsk Sea is intensified by the amplified wind, and then the transport of the salinity anomaly (to the DSW formation region) is also enhanced.

[6] However, the horizontal resolution is $1^{\circ}$ in Nakamura et al.'s [2006] study and $0.5^{\circ}$ in Matsuda et al.'s [2009] study. Such horizontal resolution is too coarse to well resolve the northwestern coastal polynya, which is several tens of kilometers in width [Martin et al., 1998]. The estimate of the DSW formation rate by Nakamura et al. [2006] is smaller than those obtained by observational studies, and it is probably attributable to the ice production in the models being smaller than recent observational estimates [Ohshima et al., 2003; Nihashi et al., 2009] due to the relatively coarse horizontal resolution. The observational study by Martin et al. [1998] showed that the DSW formation rate increases (decreases) in a year of relatively stronger (weaker) wintertime offshore wind on the northwestern coast of the Okhotsk Sea. Stronger (weaker) offshore wind strengthens (weakens) sea ice divergence along the coast, ice production, and brine rejection. The ice production, however, did not increase by amplified wind stress in the numerical modeling study by Matsuda et al. [2009], which may also be attributable to too coarse horizontal resolution. These previous numerical modeling studies have probably underestimated the role of the coastal polynya as a source of DSW formation.

[7] In this study, sensitivity of DSW formation to boundary conditions is examined using an ice-ocean coupled model with horizontal resolution of several kilometers in the northern part of the Okhotsk Sea. Nakamura et al. [2006] and Matsuda et al. [2009] defined DSW by a fixed threshold for density and temperature, which is based on the observational study by Gladyshev et al. [2000], in discussing the 
sensitivity of DSW formation. This way of defining DSW is useful to validate numerical results directly by observational results. From the viewpoint of water mass formation processes, on the other hand, DSW should be characterized as a water directly influenced by brine rejection. Applying an observation-based definition to modeling results could lead to incorrectly counting water not associated with brine as DSW, as changes in forcing could modify the property of the precursor water for DSW. Such influences should be separated in assessing the sensitivity of DSW formation. In this study, DSW is defined independently for each experiment such that its seasonal change is consistent with what is observed when the DSW sensitivity is discussed. As shown in section 3.2, this definition of DSW properly extracts the water directly influenced by brine.

[8] The water influenced by brine is found not only under the coastal polynya but also in the offshore of the northern shelf region in our model. Existence of such a water is supported by observation. This water is included in DSW in this study. Such offshore formation of DSW has not been pointed out so far, so we discuss its mechanism and validity.

[9] This paper is organized as follows. Numerical setup of the model is described, and forcings for each experiment are provided in section 2 . In section 3 , performance of the model with regard to DSW formation is first examined where DSW is defined by a common density threshold for all experiments. Then, it is redefined with different density thresholds depending on experiments and the sensitivity of DSW formation is assessed. Finally, these results are summarized, and this study is concluded in section 4 .

\section{Model Configuration}

\subsection{Numerical Model}

[10] The ocean general circulation model employed in this study is the Center for Climate System Research (CCSR) Ocean Component Model developed at CCSR [Hasumi, 2006]. By virtue of its generalized curvilinear horizontal coordinate, one can arrange a computational grid system to realize high horizontal resolution for a region of focus with efficiently represented interactions with surrounding regions. Figure $2 \mathrm{a}$ shows the model domain and the computational grid system in this study. The model domain covers the North Pacific. The horizontal resolution is up to $790 \mathrm{~km}$ in the South Pacific, while it is less than $8 \mathrm{~km}$ in the northern part of the Okhotsk Sea to improve resolution of the northwestern coastal polynya (Figure 2b). The model topography is basically made from Earth Topography 5 Minute (ETOPO5) data [National Geophysical Data Center, 1988]. The topography data made by Ono et al. [2006] is also used around the Kashevarov Bank because of the inaccuracy of the ETOPO5 data in that region. The vertical coordinate system is a hybrid of $\sigma$ and $z$, where $\sigma$ is the normalized depth. There are 36 vertical levels; the $\sigma$ coordinate is applied to the five uppermost levels between the free surface and $50 \mathrm{~m}$ below the mean surface level, and the $z$ coordinate is applied to the remaining levels. The thickness of the levels in the $z$ coordinate region varies from 20 to $500 \mathrm{~m}$.

[11] To better represent transport of water on the continental shelf by eddies, the momentum advection is discretized by the Takano-Ohnishi scheme [Ishizaki and Motoi, 1999], in which pseudoenstrophy is preserved and up/downslope momentum advection is taken into account. A third-order advection scheme is used for the tracer advection [Leonard et al., 1993; Hasumi and Suginohara, 1999]. A biharmonic version of Smagorinsky lateral viscosity [Smagorinsky, 1963; Griffies and Hallberg, 2000] is employed. The coefficient for horizontal harmonic eddy diffusion is proportional to grid width and it takes $0.4-1.0 \mathrm{~m}^{2} \mathrm{~s}^{-1}$ in the northern shelf region. A mixed layer scheme by Noh and Kim [1999], which is based on the level 2.5 turbulence closure of Mellor and Yamada [1982], is employed for diagnosing the vertical diffusivity and viscosity. The background vertical viscosity isset to $1 \times 10^{-4} \mathrm{~m}^{2} \mathrm{~s}^{-1}$. The background vertical diffusion coefficient is $1 \times 10^{-5} \mathrm{~m}^{2} \mathrm{~s}^{-1}$ at the sea surface and gradually increases up to $3 \times 10^{-4} \mathrm{~m}^{2} \mathrm{~s}^{-1}$ with depth [Tsujino et al., 2000]. Vertical convection due to unstable stratification is represented by the convective adjustment, where the unstable water column is artificially homogenized with conserving heat and salt. The sea ice model is based on two-category thickness representation, zero-layer thermodynamics [e.g., Semtner, 1976], and dynamics with elastic-viscous-plastic rheology [Hunke and Dukowicz, 1997].

[12] Two virtual tracers, $S_{B C}$ and $S_{B o}$, are introduced to the model to clarify regions in which brine is rejected and distribution of the water is influenced by the brine. $S_{B C}$ and $S_{B o}$ represent the parts of salinity in practical salinity unit (psu), which originate from the brine rejected in coastal and offshore regions, respectively. Advection and diffusion of these tracers are calculated in the same manner as those of temperature and salinity. The boundary conditions for $S_{B C}$ and $S_{B o}$ are explained in section 2.2.

\subsection{Boundary Conditions}

[13] Temperature and salinity are restored to monthly climatological data by Polar Science Center Hydrographic Climatology (PHC) [Steele et al., 2001] to the south of $15^{\circ} \mathrm{S}$. Sea surface salinity (SSS) is also restored to the monthly PHC data with a time scale of 5 days over the whole domain, but the Okhotsk Sea is excluded to properly represent salinity transport in the upper layer.

[14] Experiments conducted in this study are listed in Table 1. In all the experiments, the sea surface momentum and heat fluxes are calculated from the monthly climatological data set by Röske [2001], which is based on the European Centre for Medium-Range Weather Forecasts (ECMWF) reanalysis. The bulk formulae of Kara et al. [2000] are used for the flux calculation. The Amur runoff is temporally invariant in Röske's data set. On the other hand, most of the Amur runoff flows out from May to October, and its amount is small from November to April in the observed long-term monthly mean [Ogi et al., 2001]. Monthly Amur runoff data is constructed by multiplying the temporally invariant data of Röske [2001] by monthly factors read from the line chart of Ogi et al. [2001]. In the Okhotsk Sea, the sea surface freshwater flux consists of evaporation, precipitation, and river runoff of Röske's data set with the monthly Amur runoff. These sea surface fluxes are applied in Runs 1 and 2. Figure 3 shows a comparison of river runoff data in the Okhotsk Sea between the data set used in this study and in situ observation [Perry et al., 1996]. The annual mean Amur runoff is about $10^{4} \mathrm{~m}^{3} \mathrm{~s}-1$ in both data sets. On the other hand, the total amount of annual mean river runoff in the Okhotsk Sea, except for the Amur River, is $6644 \mathrm{~m}^{3} \mathrm{~s}^{-1}$ in 

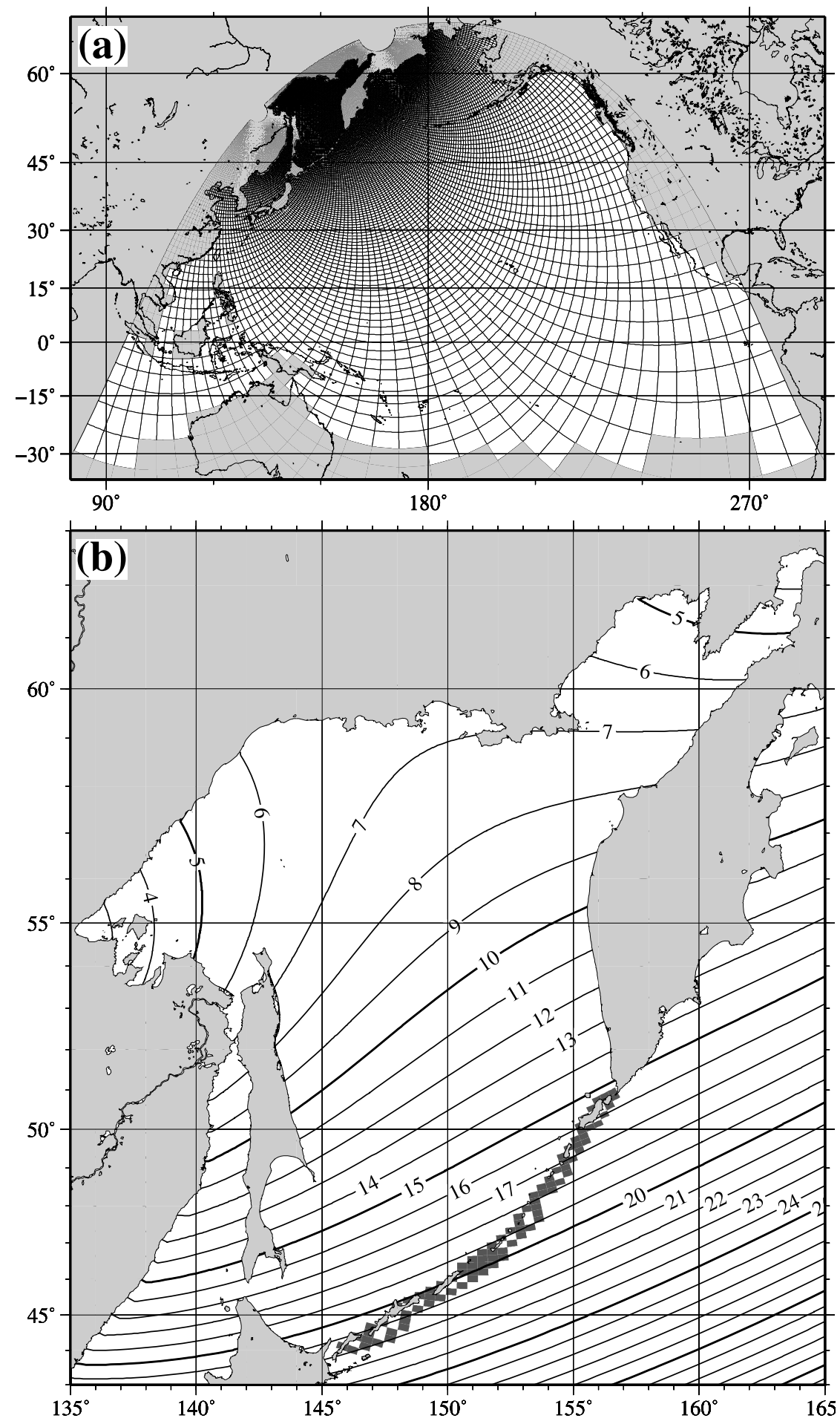

Figure 2. (a) Computational grid of the model. (b) Horizontal resolution around the Okhotsk Sea (km). Tidal mixing is taken into account in the dark gray region around the Kuril Islands in Run 2, Run 3, and Run 4.

the data used in this study, while it is $2205 \mathrm{~m}^{3} \mathrm{~s}^{-1}$ in Perry et al.'s [1996] study. The Okhotsk river runoff of Röske's data set might include substantial errors associated with biases in the original reanalysis. On the other hand, Perry et al. [1996] only counted runoff of major rivers, so the contribution from small rivers and underground flows are not accounted for. There is an uncertainty in the total amount of river runoff into the Okhotsk Sea. Sensitivity of DSW 
Table 1. List of Experiments

\begin{tabular}{lrrrrrr}
\hline & Run 1 & Run 2 & Run 3 & Run 4 & Run 5 \\
\hline Wind speed $\times 1.25$ & & & yes & yes & \\
Wind stress $\times 1.25^{2}$ & & & yes & yes & yes \\
Tidal mixing effect around Kuril & & yes & yes & yes & yes \\
$\quad$ Islands & & & & & \\
Amur River runoff & yes & yes & yes & yes & yes \\
Other runoffs into the Okhotsk Sea & yes & yes & yes & & yes \\
\hline
\end{tabular}

formation to this uncertainty is investigated in Run 4 by removing all runoff into the Okhotsk Sea, except for the Amur runoff.

[15] Enhanced vertical mixing due to tides around the Kuril Straits is taken into account in Runs 2, 3, and 4, where the background vertical diffusivity coefficient is set to $2 \times$ $10^{-2} \mathrm{~m}^{2} \mathrm{~s}^{-1}$ over the sill along the Kuril Islands shallower than $2300 \mathrm{~m}$ deep (dark gray region in Figure 2b). Nakamura et al. [2006] adopted the value of $2 \times 10^{-2} \mathrm{~m}^{2} \mathrm{~s}^{-1}$ in their main experiment based on the results of previous studies [Nakamura et al., 2000; Nakamura and Awaji, 2004]. Matsuda et al. [2009] also adopted this value in their control run. This value is also adopted in this study to make a comparison with these previous studies under the same representation of the tidal mixing.

[16] Ohshima et al. [2003] pointed out that the sea surface wind speed reanalyzed by ECMWF is smaller than in situ observation by about $25 \%$ in the Okhotsk Sea. Numerical

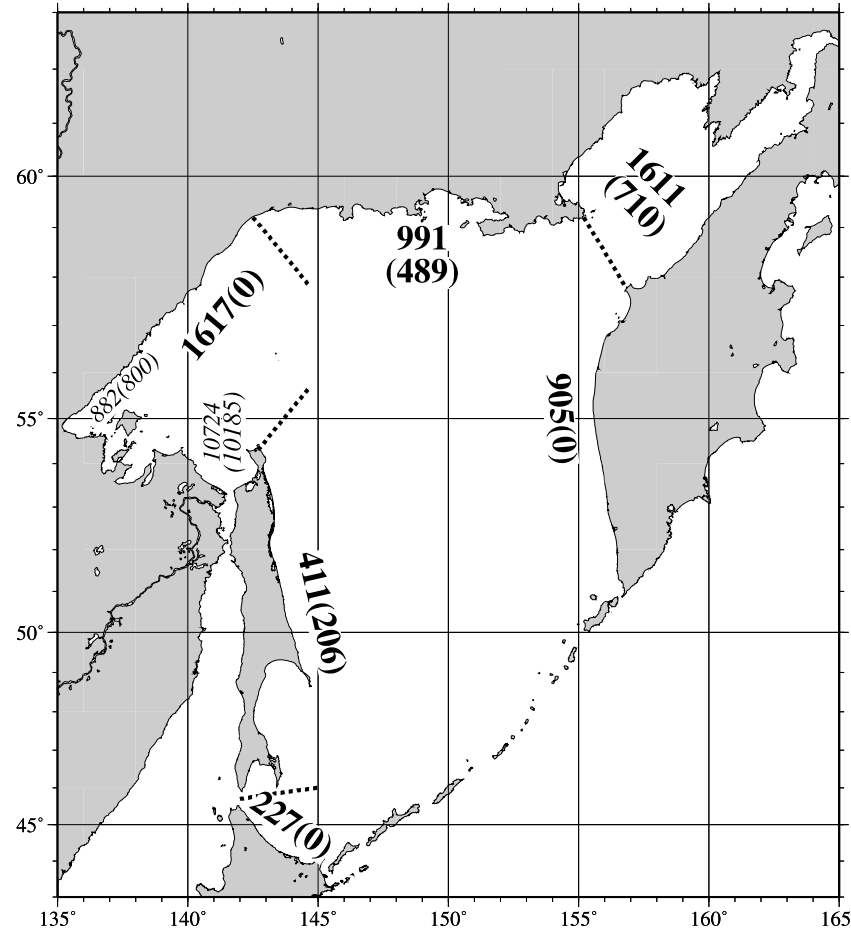

Figure 3. Annual mean coastal runoff (bold) and riverine runoff (italic) from the Amur and Uda, which flows into the western edge of the Okhotsk Sea, for a reanalysis-based climatology (values outside of parentheses) [Röske, 2001] and an observation-based data set (values in parentheses) [Perry et al., 1996]. The units are $\mathrm{m}^{3} \mathrm{~s}^{-1}$. Coastal runoff is defined for each segment of the coastline divided by the dotted lines.
Table 2. Anuual Mean Formation Rate of DSW Estimated by Observational Studies

\begin{tabular}{|c|c|c|}
\hline Study & $\begin{array}{c}\text { DSW Formation } \\
\text { Rate }\end{array}$ & $\begin{array}{l}\text { Region for } \\
\text { Estimation }\end{array}$ \\
\hline Alfultis and Martin [1987] & $0.1-0.7 \mathrm{~Sv}$ & $\begin{array}{l}\text { Northwestern shelf } \\
\left.\text { (west of } 150^{\circ} \mathrm{E}\right)\end{array}$ \\
\hline Martin et al. [1998] & $0.20-0.36 \mathrm{~Sv}$ & Major coastal polynyas \\
\hline Gladyshev et al. [2000] & $0.24-0.50 \mathrm{~Sv}$ & Major coastal polynyas \\
\hline Itoh et al. [2003] & $0.67 \mathrm{~Sv}$ & $\begin{array}{l}\text { Northern shelf, except } \\
\text { for Shelikhov Bay }\end{array}$ \\
\hline Shcherbina et al. [2004b] & $0.27 \mathrm{~Sv}$ & $\begin{array}{l}\text { Northwestern } \\
\text { coastal polynya }\end{array}$ \\
\hline Nihashi et al. [2009] & $0.36 \mathrm{~Sv}$ & $\begin{array}{l}\text { Northwestern } \\
\text { coastal polynya }\end{array}$ \\
\hline
\end{tabular}

studies by Simizu and Ohshima [2002] and Simizu and Ohshima [2006] have adopted the ECMWF wind stress amplified by factors of the square of 1.30 and 1.25 , respectively. The ECMWF wind stress is also used by Matsuda et al. [2009], and they reported that a realistic circulation is reproduced on the isopycnal surface of $26.8 \sigma_{\theta}$ with the wind stress amplified by a factor of 1.5 , nearly equal to the square of 1.23. In this study, too, the wind speed and stress are amplified by 1.25 and the square of 1.25 , respectively, in the Okhotsk Sea in Runs 3 and 4. In this regard, winds in the Okhotsk Sea for Runs 1 and 2 are weaker than the realistic climatological mean by $20 \%$. This magnitude of reduction coincides with the standard deviation of the interannual change in wind speed in ice period, as mentioned in section 1 . Therefore, a typical range of variation is obtained for DSW formation by this sensitivity experiment. Winds affect not only wind stress but also sensible and latent heat fluxes through the dependence of bulk formulae on wind speed. Sea ice production is affected by both of them, which is the case for Runs 3 and 4 . In order to separate these effects, an additional experiment, Run 5, is conducted where wind stress is amplified but wind speed used in the heat flux calculation is not.

[17] For $S_{B C}$ and $S_{B o}$, a no-flux condition is applied at lateral and bottom boundaries. The no-flux condition is also applied at the sea surface from the beginning of model integration to the end of September of the 15th year. After that the sea surface boundary conditions are given by

$$
\begin{gathered}
K_{v} \frac{\partial S_{B c}}{\partial z}=\left\{\begin{array}{ll}
-\min \left(F_{S}, 0\right) & (\text { for } H \leq 125 \mathrm{~m}) \\
0 & (\text { for } H>125 \mathrm{~m})
\end{array},\right. \\
K_{v} \frac{\partial S_{B o}}{\partial z}=\left\{\begin{array}{ll}
0 & (\text { for } H \leq 125 \mathrm{~m}) \\
-\min \left(F_{S}, 0\right) & (\text { for } H>125 \mathrm{~m})
\end{array},\right.
\end{gathered}
$$

Table 3. Anuual Mean Formation Rate of the Simulated DSW

\begin{tabular}{lcc}
\hline \multicolumn{1}{c}{ Case } & $\begin{array}{c}\text { Except for } \\
\text { Shelikhov Bay }\end{array}$ & $\begin{array}{c}\text { Including } \\
\text { Shelikhov Bay }\end{array}$ \\
\hline Run 1 & $0.14 \mathrm{~Sv}$ & $0.20 \mathrm{~Sv}$ \\
Run 2 & $0.35 \mathrm{~Sv}$ & $0.46 \mathrm{~Sv}$ \\
Run 3 & $0.48 \mathrm{~Sv}$ & $0.64 \mathrm{~Sv}$ \\
Run 4 & $0.64 \mathrm{~Sv}$ & $0.84 \mathrm{~Sv}$ \\
Nakamura et al. $[2006]^{\mathrm{a}}$ & $0.13 \mathrm{~Sv}$ & $0.13 \mathrm{~Sv}$ \\
\hline
\end{tabular}

${ }^{\mathrm{a}}$ Estimation from a numerical model with sea surface boundary condition and tidal mixing effect similar to Run 2. 
Table 4. DSW Formation Rate, Except for Shelikhov Bay, in Run 4 in Subdivided by Density Ranges

\begin{tabular}{lcc}
\hline Density Layer & Run 4 & Itoh et al. [2003] \\
\hline $26.75-26.85 \sigma_{\theta}$ & $0.34 \mathrm{~Sv}$ & $0.33 \mathrm{~Sv}$ \\
$26.85-26.95 \sigma_{\theta}$ & $0.28 \mathrm{~Sv}$ & $0.27 \mathrm{~Sv}$ \\
$26.95-27.05 \sigma_{\theta}$ & $0.05 \mathrm{~Sv}$ & $0.06 \mathrm{~Sv}$ \\
$>27.05 \sigma_{\theta}$ & $0.05 \mathrm{~Sv}$ & - \\
\hline
\end{tabular}

where $H$ is the depth of seafloor. $F_{S}$ denotes the salinity flux at the sea surface due to sea ice melting or formation and is negative when sea ice forms [see Hasumi, 2006].

[18] In each experiment, the model is integrated for 16 years from a state of rest with the temperature and salinity fields of the PHC January data. $S_{B C}$ and $S_{B o}$ are initially set to zero. Sea ice formation, SSS, and DSW formation reach a nearly steady state in the Okhotsk Sea. Results of the 16th model year are used in the following analyses.

\section{Results}

\subsection{Performance of the Model}

[19] Several observational studies have estimated the DSW formation rate from surface heat loss or hydrographic data (Table 2). Most of the estimations are limited to the northwestern coastal polynya or the major coastal polynyas in the northern shelf region. Itoh et al. [2003] estimated the DSW formation rate in the whole northern shelf region, excluding the regions around Shelikhov Bay. The numerical modeling study by Nakamura et al. [2006] also estimated the formation rate in the Okhotsk Sea. DSW formation rates are defined here by the fixed temperature and density of Itoh et al. [2003] for validating the model performance.

[20] Itoh et al. [2003] defined DSW as a water on the northern shelf, except for Shelikhov Bay, with density within 26.75-27.05 $\sigma_{\theta}$ and temperature less than $0^{\circ} \mathrm{C}$ and its formation rate as the total volume of DSW found in climatologically averaged data from spring to summer divided by 1 year. The same definition is employed to analyze the model results, using the period from April to September for estimating the formation rate. Two estimates are presented for the formation rate: including and excluding Shelikhov Bay. The latter, where calculation is limited to the west of $153^{\circ} \mathrm{E}$, is to facilitate comparison with the results of Itoh et al. [2003].

[21] The DSW formation rate, except for Shelikhov Bay, in Run 1 is much smaller than the observational estimate (Table 3). DSW formation increases by adding the effects of

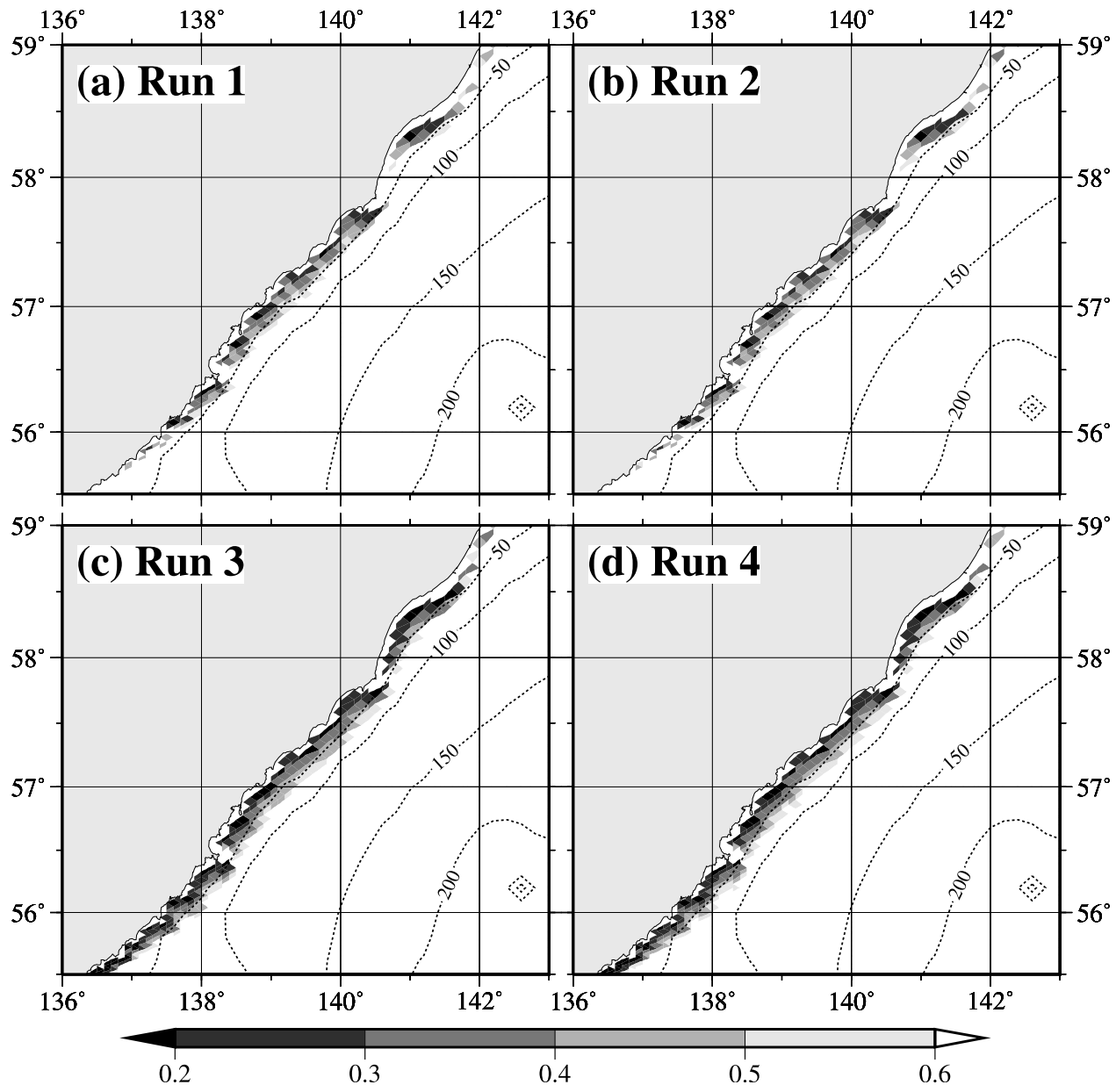

Figure 4. Horizontal distributions of monthly sea ice concentration in January around the northwestern coast of the Okhotsk Sea simulated in (a) Run 1, (b) Run 2, (c) Run 3, and (d) Run 4. Contours represent the bathymetry $(\mathrm{m})$. 
$136^{\circ} 138^{\circ} 140^{\circ} 142^{\circ} 144^{\circ} 146^{\circ} 148^{\circ} 150^{\circ} 152^{\circ} 136^{\circ} 138^{\circ} 140^{\circ} 142^{\circ} 144^{\circ} 146^{\circ} 148^{\circ} 150^{\circ} 152^{\circ}$
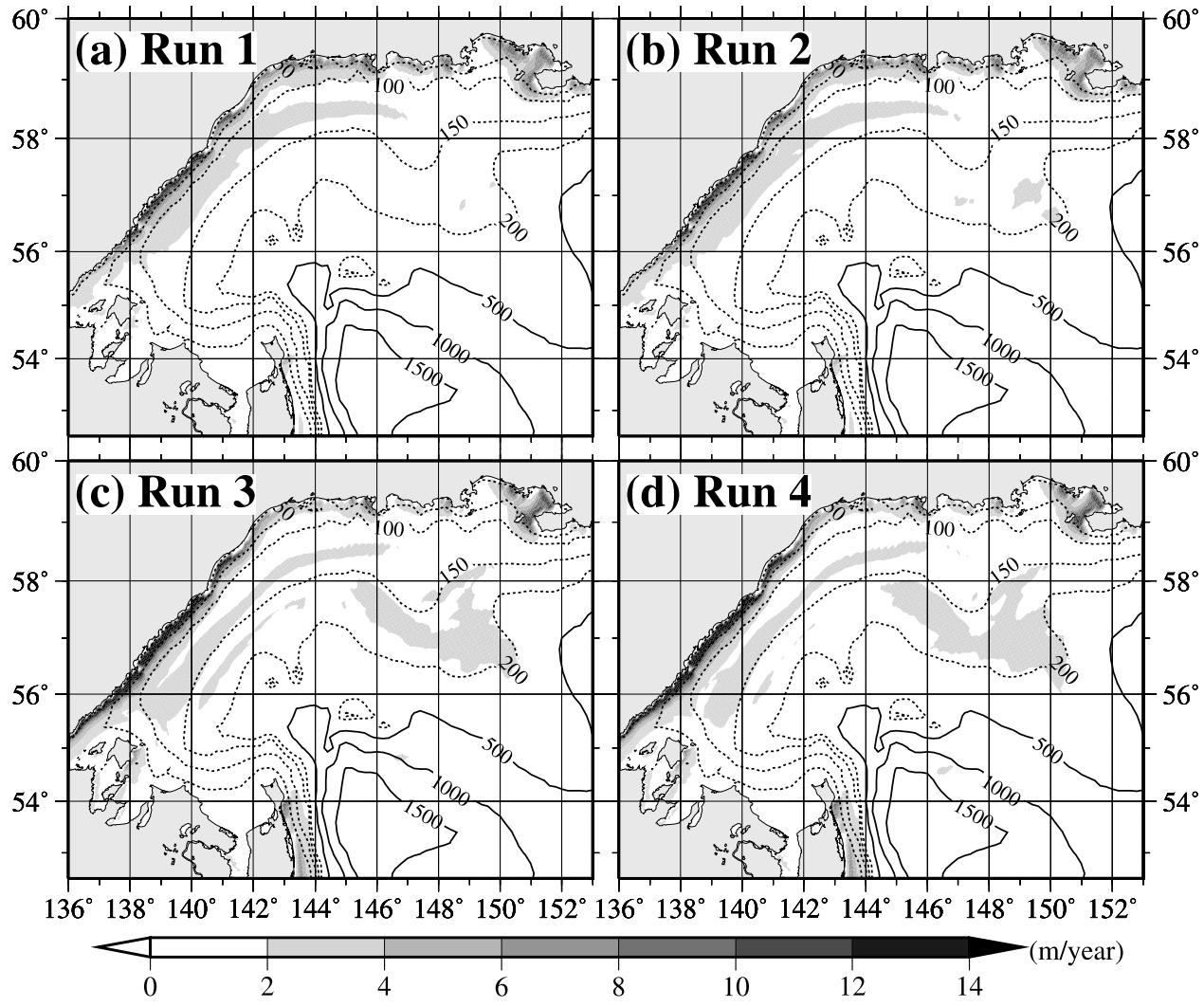

Figure 5. Horizontal distributions of annual sea ice production in the northwestern part of the Okhotsk Sea simulated in (a) Run 1, (b) Run 2, (c) Run 3, and (d) Run 4 (m/yr). Contours represent the bathymetry (m).

tides around the Kuril Straits (Run 2), amplifying the wind (Run 3), and reduction of runoff (Run 4). The formation rate in Run 4 is near the observational estimate and also shows good agreement in each density range (Table 4 ). The result of Run 4, on the other hand, shows shelf water denser than $27.02 \sigma_{\theta}$, which have never been reported by observations [e.g., Kitani, 1973; Shcherbina et al., 2003]. Such tendency is also recognized in the other experiments of this study. Kowalik and Polyakov [1998] showed that tidal energy dissipation is relatively large around the northern shelf region, which implies strong tidal mixing in that region. Mixing of brine and surrounding water in the northern shelf region might be insufficient in our model due to our negligence of the tidal mixing effect in that region. This is a possible cause for the above mentioned problem of too dense DSW. There is a further possibility that the horizontal resolution of this model is still too coarse to represent mixing due to baroclinic eddies in the northern shelf region,

Table 5. Annual Ice Production in the Okhotsk Sea

\begin{tabular}{lc}
\hline \multicolumn{1}{c}{ Case } & Ice Production $\left(10^{11} \mathrm{~m}^{3}\right)$ \\
\hline Run 1 & 8.9 \\
Run 2 & 9.4 \\
Run 3 & 12.0 \\
Run 4 & 12.2 \\
Nakamura et al. $[2006]$ & 2.4 \\
Observational estimation & 13 \\
[Ohshima et al., 2003] & \\
\hline
\end{tabular}

as the deformation radius, which is estimated to be $5-10 \mathrm{~km}$ in this region, is only marginally resolved by the model. The formation rate, including Shelikhov Bay, in each experiment is $30-40 \%$ larger than the formation rate, excluding Shelikhov Bay. Gladyshev et al. [2000] showed that the polynyas in Shelikhov Bay produce $25-40 \%$ of the DSW. This model adequately represents Shelikhov Bay's contribution to the DSW formation. The formation rates in the northern shelf region in Runs 2, 3, and 4 are considerably larger than that obtained by the numerical experiment of Nakamura et al. [2006], where the vertical diffusion coefficient is also raised to $2 \times 10^{-2} \mathrm{~m}^{2} \mathrm{~s}^{-1}$ around the Kuril Islands.

[22] The northwestern coastal polynya, which is recognized as the region of low ice concentration along the northwestern coast, has less ice than in the previous numerical modeling studies (Figure 4). The simulated ice concentration is less than 0.6 within $20 \mathrm{~km}$ from the coast in January and that in the grid cells closest to the coast is less than 0.25 until the end of February. The ice concentration in most of the

Table 6. Salinity in November Averaged in the Layer Shallower Than $100 \mathrm{~m}$ Depth in the Northern Shelf Region and Annual Mean Bottom Density

\begin{tabular}{ccc}
\hline Case & Salinity $(\mathrm{psu})$ & Bottom Density $\left(\sigma_{\theta}\right)$ \\
\hline Run 1 & 32.89 & 26.72 \\
Run 2 & 33.02 & 26.80 \\
Run 3 & 33.04 & 26.83 \\
Run 4 & 33.14 & 26.88 \\
\hline
\end{tabular}




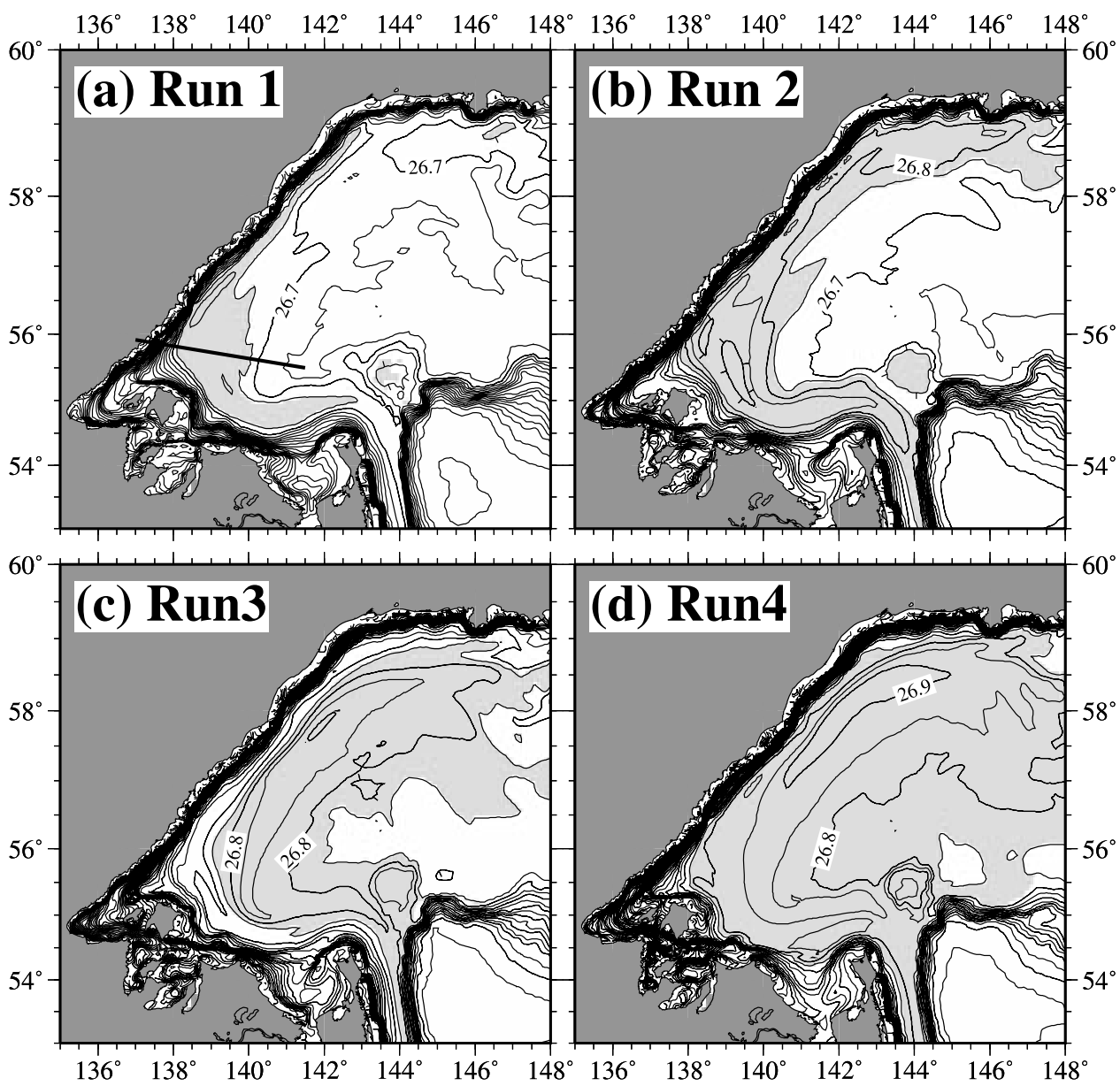

Figure 6. Horizontal distributions of bottom density around the northwestern shelf in September simulated in (a) Run 1, (b) Run 2, (c) Run 3, and (d) Run 4 (contour interval is $0.05 \sigma_{\theta}$ ). In shaded regions, the bottom density and temperature are larger than $26.75 \sigma_{\theta}$ and colder than $0^{\circ} \mathrm{C}$, respectively, which match the DSW definition by Itoh et al. [2003]. A solid line around $56^{\circ} \mathrm{N}$ in Figure $6 \mathrm{a}$ indicates the observation line of Shcherbina et al. [2003].

experiments by Matsuda et al. [2009] is larger than 0.8 at the end of January in the grid cells closest to the coast whose width is about $30 \mathrm{~km}$. Such discrepancy is likely to be caused by the difference of the horizontal resolution. Sea ice production exhibits a peak in the simulated northwestern coastal polynya in every experiment (Figure 5). The annual sea ice production in the Okhotsk Sea (Table 5) is close to a recent observational estimate by Ohshima et al. [2003], although it is smaller than a newer observational estimate based on higher-resolution data [Nihashi et al., 2009]. The value in each experiment is much larger than that shown by Nakamura et al. [2006]. The more realistic sea ice production in this study results in a larger amount of brine rejection and DSW formation.

[23] Bottom density (Table 6) also increases due to the intensification of DSW formation by the addition of tidal mixing effect, the amplification of the wind, and the reduction of runoff. The region occupied by DSW expands as DSW formation increases (Figure 6). The observed distribution of bottom density in September 1999 around $56^{\circ} \mathrm{N}$ (along the thick solid line in Figure 6a) [Shcherbina et al., 2003] shows its maximum near $140^{\circ} \mathrm{E}$ with density larger than $26.9 \sigma_{\theta}$.
The maximum of the bottom density larger than $26.85 \sigma_{\theta}$ is also recognized on the same line in Runs 3 and 4, in which the wind forcing is amplified. This agreement also supports the underestimation of the ECMWF wind and validity of the amplification suggested by Ohshima et al. [2003].

\subsection{Redefinition of DSW}

[24] Here, we would like to redefine DSW as a water directly influenced by brine rejection. From this stand point, an increase in the DSW formation rate should be accompanied by an increase in sea ice production. The analysis in section 3.1 shows that the tidal mixing effect and the removal of runoff raise the DSW formation rate, while sea ice production is barely affected. This indicates that the change of the DSW formation rate given in section 3.1 might just reflect the change of densities in the upper layer of the Okhotsk Sea, as Nakamura et al. [2006] suggested. In order to separate the effect of density changes from the estimate of the DSW formation rate, DSW should be defined by different density thresholds depending on experiments, which are decided so as to be consistent with 


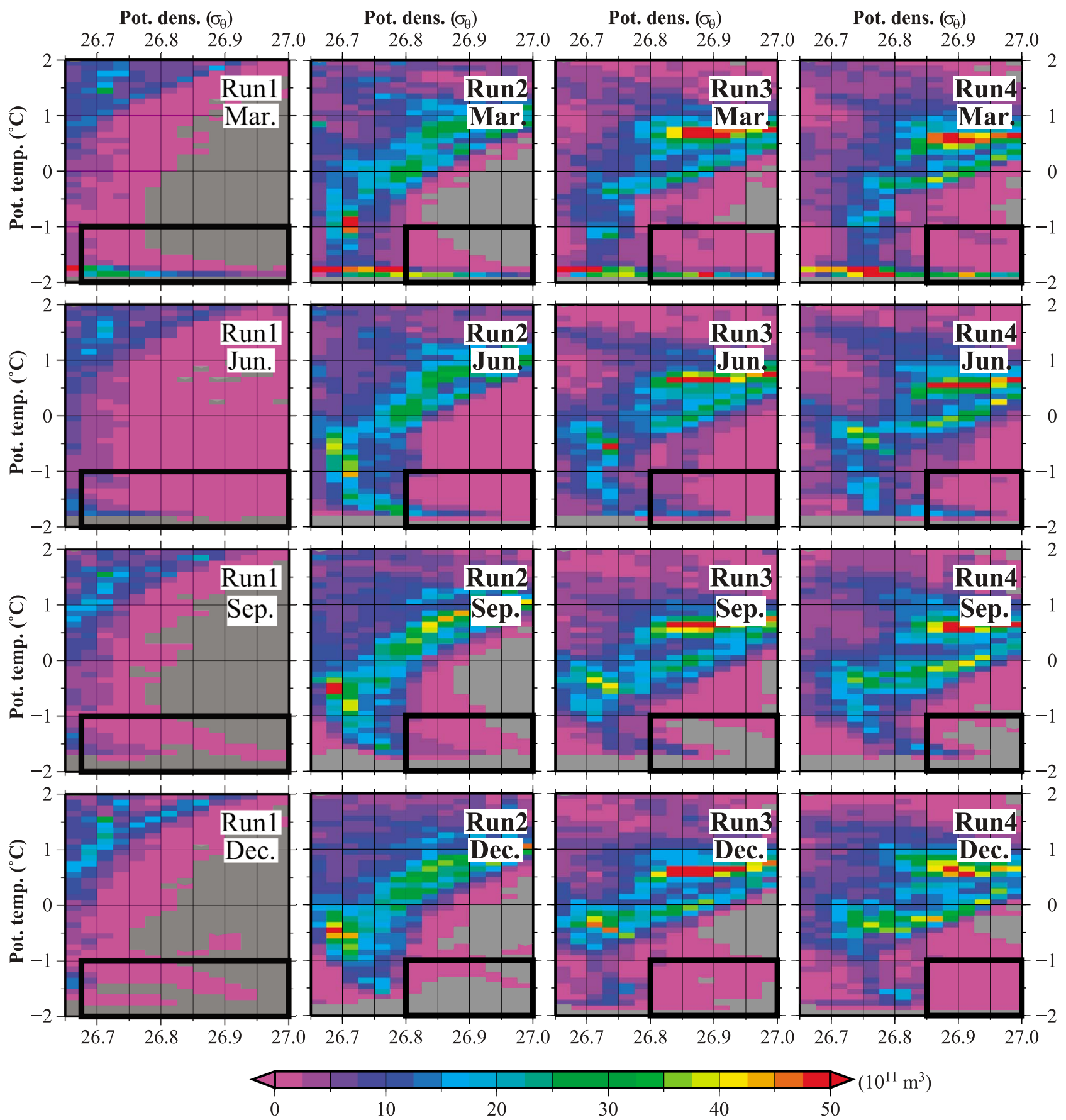

Figure 7. Water volume within $0.025 \sigma_{\theta} \times 0.1^{\circ} \mathrm{C}$ bins in the Okhotsk Sea. Thick rectangles indicate the DSW range of each experiment defined in section 3.2. Gray areas indicate that there is no water within these density and temperature ranges in the Okhotsk Sea.

the observed knowledge for seasonal change of its volume by Shcherbina et al. [2004b].

[25] Figure 7 shows seasonal variations of water volume in the Okhotsk Sea in each bin of density and temperature ranges. Thick rectangles in Figure 7 indicate that the water is colder than $-1^{\circ} \mathrm{C}$ and denser than the threshold shown in Table 7. Hereafter, we call this water the cold dense water. Figure 8 shows distributions of the cold dense water every 3 months in each experiment. In every experiment, most of the cold dense water exists over the northern shelf region,
Table 7. Density Threshold for the Redefined DSW and Its Annual Mean Formation Rate ${ }^{\mathrm{a}}$

\begin{tabular}{|c|c|c|}
\hline Case & Density Threshold $\left(\sigma_{\theta}\right)$ & DSW Formation Rate (Sv) \\
\hline Run 1 & 26.675 & 0.69 \\
\hline Run 2 & 26.800 & 0.76 \\
\hline Run 3 & 26.800 & 0.94 \\
\hline Run 4 & 26.850 & 0.97 \\
\hline
\end{tabular}

${ }^{\mathrm{a}} \mathrm{DSW}$ is here defined as water colder than $-1^{\circ} \mathrm{C}$ and denser than the density threshold in each experiment, and its annual mean formation rate is here a difference between maximum and minimum amounts of DSW over a 1 year period (see section 3.2). 


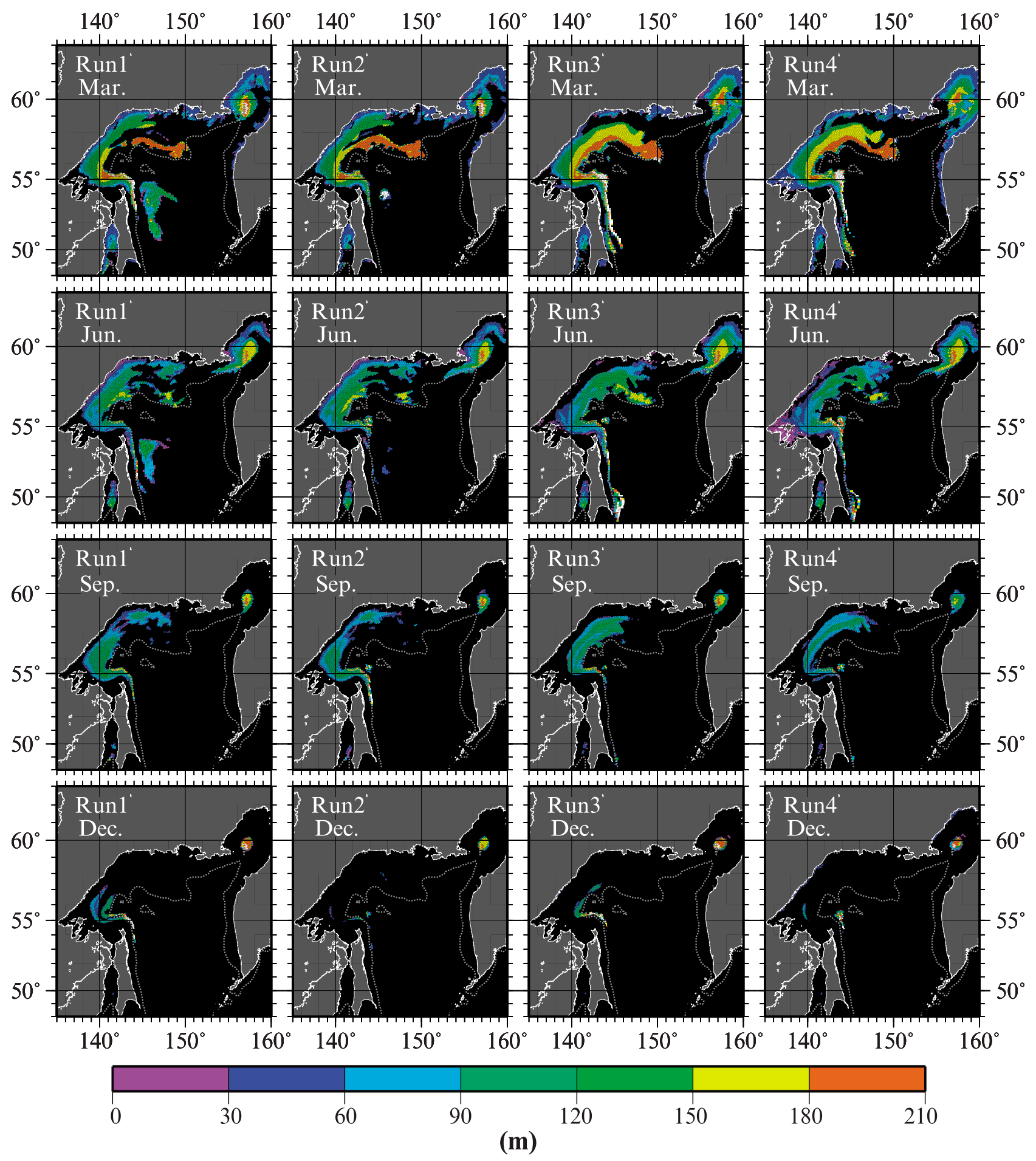

Figure 8. Horizontal distributions of the water thickness colder than $-1^{\circ} \mathrm{C}$ and denser than the density threshold, which is specified in each experiment (Table 7), every 3 months. The gray line is the isobath of $200 \mathrm{~m}$ depth.

and its temperature is near the freezing point (around $-1.8^{\circ} \mathrm{C}$ ) in March. These facts are consistent with the characteristics of DSW as the water formed through the sea ice production in the northern shelf region. The density thresholds in Table 7 are decided by the smallest density, at which all of the denser water vanishes from the northern shelf region just before the ice period.
[26] The sum of the vertically averaged $S_{B C}$ and $S_{B o}$ in March exhibits a distribution similar to the cold dense water thickness both in Runs 2 and 3 (Figure 9). Such similarity is also seen in Runs 1 and 4 (not shown). The cold dense water exists in the whole water column in most of the northern shelf region during the ice period because of vertical mixing associated with brine-driven convection in every experi- 

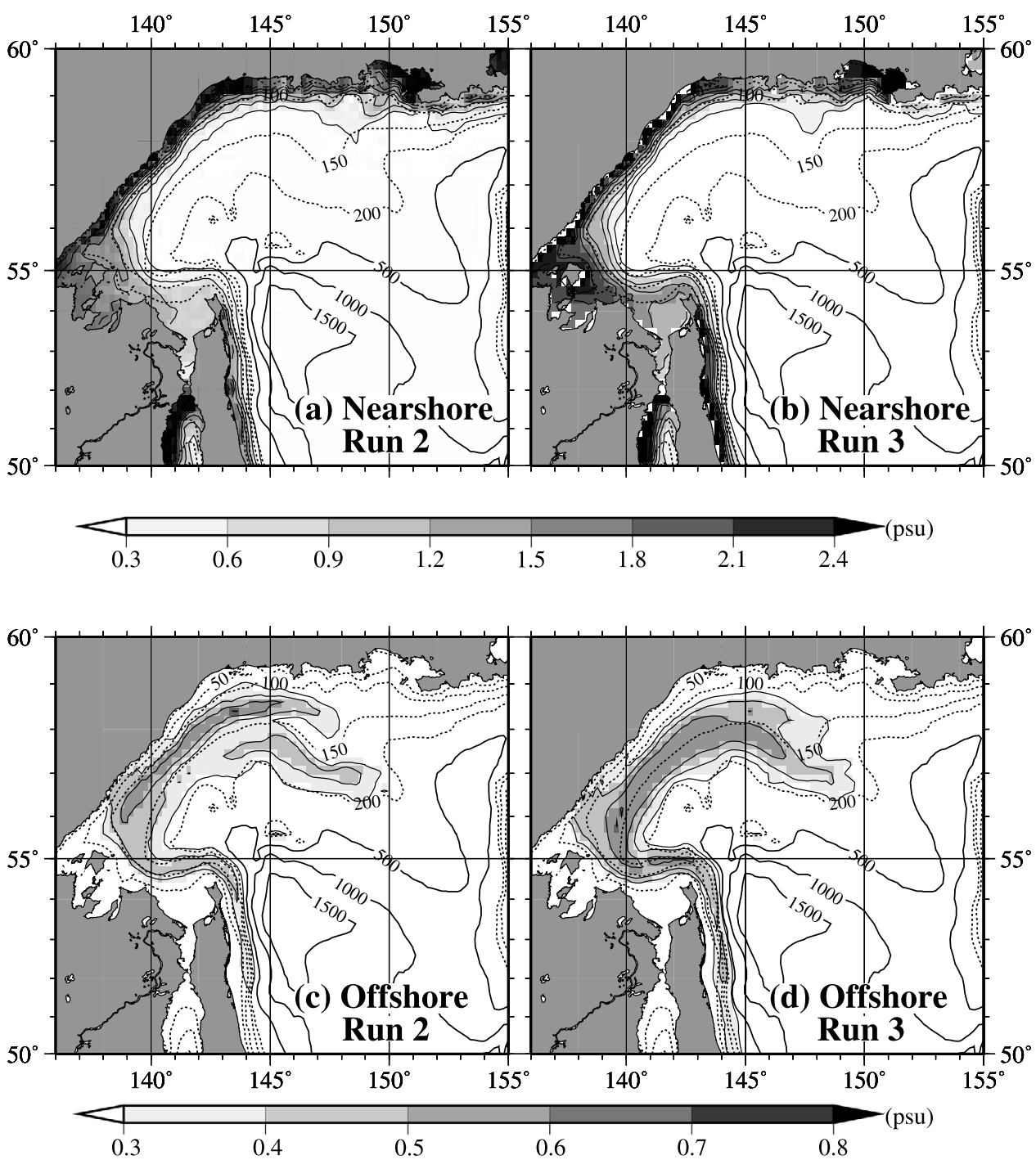

Figure 9. Horizontal distributions of vertically averaged $S_{B C}$ simulated in (a) Run 2 and (b) Run 3 and $S_{B o}$ simulated in (c) Run 2 and (d) Run 3.

ment. The distribution of the cold dense water in the northern shelf region is almost consistent with that of $S_{B C}$ and $S_{B o}$. Water on the northern shelf flows cyclonically (see Figures $11 \mathrm{c}$ and $11 \mathrm{~d}$ ). The cold dense water is transported by this current, flows out from the northern shelf region through the continental slope of the Sakhalin, and almost vanishes in December in every experiment. This seasonal change is also consistent with that of the DSW volume mentioned in section 1. DSW is redefined by this cold dense water in the northern shelf region in each experiment. Figure 10 shows the time series of DSW volume in each experiment. It increases from January to April due to the sea ice formation and decreases from May to December as a result of the flushing from the shelf and mixing with surrounding water. There is little DSW in the northern shelf region in December as mentioned in section 1. The DSW formation rate is redefined as the difference between DSW volume in April and December divided by 1 year.

[27] The volume of the cold dense water, which flows out from the northern shelf region during the ice period, amounts

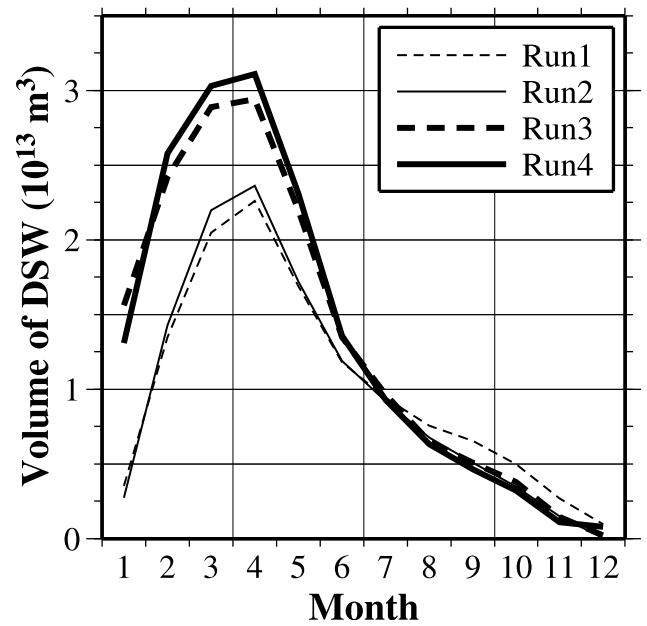

Figure 10. Time series of the DSW volume redefined in each experiment. 
Table 8. Volume of the Cold Dense Water Flowing Out From the Northern Shelf Region Through Section A During a Year and During the Ice Period ${ }^{\mathrm{a}}$

\begin{tabular}{lcc}
\hline Case & Ice Period $\left(10^{12} \mathrm{~m}^{3}\right)$ & Annual $\left(10^{12} \mathrm{~m}^{3}\right)$ \\
\hline Run 1 & 2.1 & 9.1 \\
Run 2 & 2.0 & 14.3 \\
Run 3 & 11.4 & 35.1 \\
Run 4 & 9.1 & 31.5 \\
\hline
\end{tabular}

${ }^{\mathrm{a}}$ See Figure 1.

to $10-30 \%$ of its annual volume in every experiment (Table 8). This water, however, is substantially modified from DSW due to entrainment, and its water property is also different from that of DSW in each experiment. Then, this portion is not counted as the redefined DSW, and the redefined DSW formation rate ignores its volume.

\subsection{DSW Formation in Offshore Region}

[28] We discuss the DSW formed in the offshore of region of the northern shelf seen in the model result before the discussion of the DSW formation. The DSW layer thickness in every experiment is larger than $150 \mathrm{~m}$ in the offshore region of the northern shelf to the west of a ridge, which extends from the northern shelf to the southeast around 144$151^{\circ} \mathrm{E}$ and $56-58^{\circ} \mathrm{N}$, in March. This part of the DSW and the ridge are hereafter called the offshore DSW and the offshore ridge (see Figure 1), respectively. In every experiment, there is a peak of sea ice production, which amounts to $2-3 \mathrm{~m} / \mathrm{yr}$, in $148-151^{\circ} \mathrm{E}$ and $56-58^{\circ} \mathrm{N}$, which corresponds to the eastern part of the offshore ridge and of the area occupied by the offshore DSW. Such a peak on the offshore ridge was once found in an observational estimate of ice production for the 2003-2004 ice period (S. Nihashi, personal communication, 2009), although its amount of sea ice production is smaller than Run 3. Hereafter, we call it the offshore peak. The ice production in the offshore region starts between $138^{\circ} \mathrm{E}$ and $140^{\circ} \mathrm{E}$ in the northwestern shelf around the end of November in every experiment. The ice edge in the offshore region rapidly migrates to the east, reaches between $148^{\circ} \mathrm{E}$ and $151^{\circ} \mathrm{E}$ of the offshore ridge region by the end of December, and then does not move much during the ice period.

[29] The wind stress in this period is directed to the southwest, which corresponds to the western part of the Aleutian low, around the offshore ridge region (Figures 11a and $11 \mathrm{~b}$ ). Sea ice produced at the eastern edge of sea ice cover is advected to the west (Figures 11e and 11f) due to the southwestward wind and the westward current in that region (Figures 11c and 11d). A high sea ice production is found around the eastern edge (shading in Figure 11) and achieved by sea ice divergence because of the southwestward wind in that region. The nearly fixed eastern edge and the divergence of the sea ice along the edge result in the offshore peak of annual ice production in that region. Such ice edge and southwestward wind on the eastern edge of the sea ice are also seen in reality from December 2003 to the middle of January 2004 (Figure 12). An observational estimate of daily ice production for this period also shows the offshore peak (S. Nihashi, personal communication, YYYY). The offshore peak in this period may be accompanied by the sea ice divergence due to the southwestward wind, the same as the model result. The offshore peak of the annual ice production in 2003-2004 may be mainly attributed to the sea ice divergence occurring in this period. The actual eastern edge on the offshore ridge occurs from December to January of most ice periods and usually vanishes after February because sea ice further extends to the region of the Tinro basin. The simulated sea ice region does not extend to the east, and the sea ice edge and offshore peak stably exist even in February. It might result in larger sea ice production around the offshore ridge than in Nihashi's (personal communication, 2009) estimation. The stable ice edge might be due to the specified sea surface forcing, as its shape coincides with the horizontal pattern of the specified forcing data set. The surface air temperature on the offshore ridge, for example, is several degrees lower than that on the Tinro basin in January and February. The nearly fixed eastern edge may be due to the biases of the forcing data set.

[30] The vertically averaged $S_{B o}$ in March is relatively high to the west of $151^{\circ} \mathrm{E}$ and is distributed roughly along isobaths in the northern shelf region both in Runs 2 and 3 (Figures 9c and 9d). The same tendency is also seen in Runs 1 and 4 (not shown). Most of this salinity enrichment originates from the offshore peak because water flows cyclonically in the northern shelf region. Such distribution of the vertically averaged $S_{B o}$ is similar to that of the offshore DSW in March in every experiment. The offshore DSW is formed mainly due to the brine rejected in the eastern part of the offshore ridge.

[31] The distributions of bottom temperature in spring observed by Gladyshev et al. [2000] show a water colder than $0^{\circ} \mathrm{C}$ around the offshore ridge, and a tongue-shaped structure of such water is also seen around the offshore ridge in the climatological temperature field on the $26.8 \sigma_{\theta}$ surface [Itoh et al., 2003]. These observed features seem to support the existence of a water formed due to brine rejection in that region. Such a structure of cold water is also seen in every experiment of this study, although it is colder than $-1^{\circ} \mathrm{C}$ in spring and colder than the observations by Gladyshev et al. [2000] and Itoh et al. [2003]. A water colder than $-1{ }^{\circ} \mathrm{C}$ should be observed in this region if such an offshore peak appears every year. Such an offshore peak was, however, found only once during the period of 2003-2009 in the sea ice production mapping of Nihashi (personal communication, 2009). Climatologically averaged data such as that by Itoh et al. [2003] might conceal the signal of this infrequent event. The bottom temperature field by Gladyshev et al. [2000] is from 1995 and 1997, and it might be the case that the offshore peak did not appear in that period. It is not possible at this stage to further validate the modeled offshore DSW formation because observed data are lacking. It is to be the subject of a future investigation.

\subsection{Sensitivity of the DSW Formation}

[32] The DSW formation rate in each experiment is shown in Table 7. The formation rate increases by $0.07 \mathrm{~Sv}$ by the tidal mixing effect around the Kuril Straits. Nakamura et al. [2006] reported that temperature decreases by the tidal mixing effect in the upper layer of the Okhotsk Sea and suggested that this cooling slightly increases the sea ice production and DSW formation in the northern part of the 

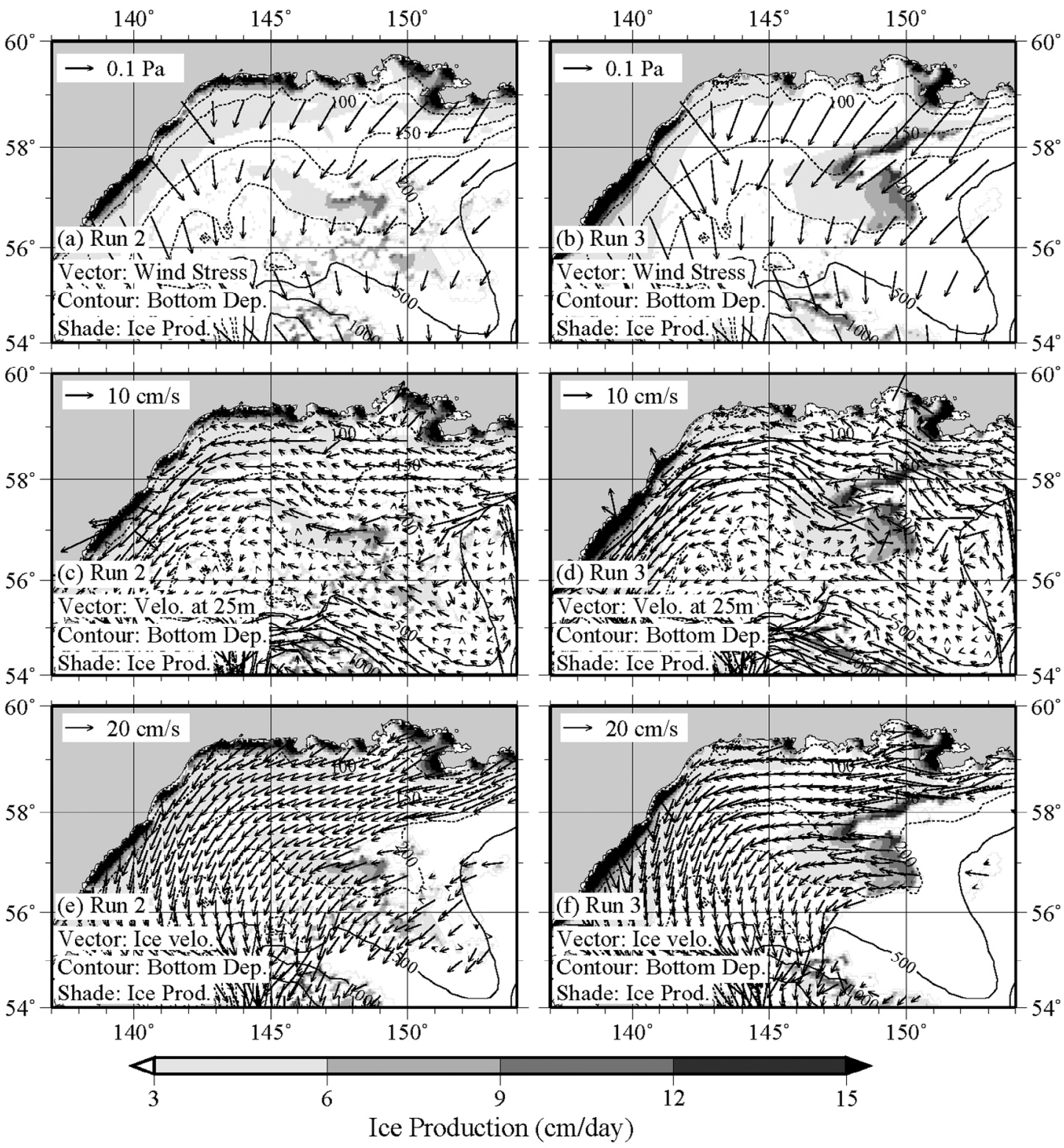

Figure 11. Horizontal distributions of wind stress simulated in (a) Run 2 and (b) Run 3, of horizontal velocity at $25 \mathrm{~m}$ depth simulated in (c) Run 2 and (d) Run 3, and sea ice velocity simulated in (e) Run 2 and (f) Run 3 on 30 January. Shading and contours are the horizontal distribution of simulated ice production on 30 January $(\mathrm{cm} / \mathrm{d})$ and bottom topography $(\mathrm{m})$, respectively.

Okhotsk Sea. In this study, the sea ice production and average sea surface temperature in the Okhotsk Sea shows the same tendency. Increase of the DSW formation rate by the reduction of river runoff, which corresponds to the difference between Runs 3 and 4, is small.

[33] On the other hand, increase from Run 2 to Run 3, which is achieved by the amplified wind in the Okhotsk Sea, is larger than those due to the other effects. The ice concentration in Run 3 is smaller than that in Run 2 along the northwestern coast due to the amplified wind (Figures $4 \mathrm{~b}$ and $4 \mathrm{c}$ ), and the ice production increases in that region (Figures $5 \mathrm{~b}$ and $5 \mathrm{c}$ ). Such intensification of ice production leads to more brine rejection. Table 9 shows the total mass of salt originating from the brine rejection in the coastal and offshore regions, $S_{B C}$ and $S_{B o}$, which are calculated by

$$
\begin{aligned}
& M_{B c}=\int \rho\left(S_{B c} \times 10^{-3}\right) d V, \\
& M_{B o}=\int \rho\left(S_{B o} \times 10^{-3}\right) d V,
\end{aligned}
$$

where $\rho$ indicates sea water density. $M_{B C}$ in Run 3 is 1.19 times as much as that in Run 2. The increase of $M_{B C}$ contributes to the increase of the DSW formation rate. Such sensitivity is qualitatively consistent with the relationship 


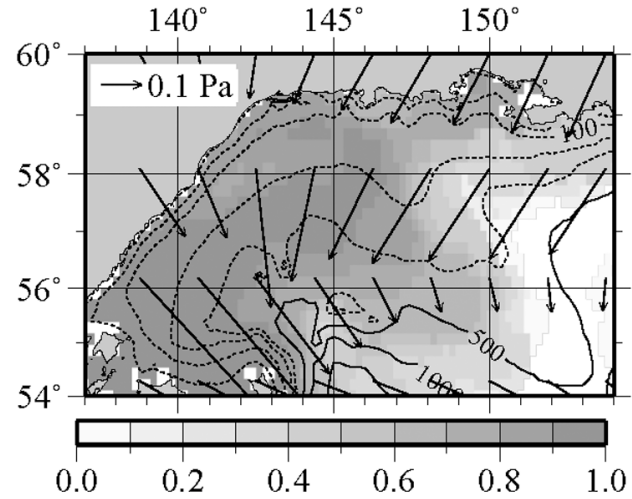

Figure 12. Sea ice concentration by National Snow and Ice Data Center averaged from 8 December 2003 to 12 January 2004 (shading). Wind stress field by NCEP/NCAR reanalysis [Kalnay et al., 1996] averaged for the same period (vectors).

between the offshore wind component on the northwestern coast and the interannual variability of DSW formation rate suggested by Martin et al. [1998]. $M_{B o}$ in Run 3 is 1.17 times as much as that in Run 2. The amount of annual sea ice production at the offshore peak in Run 3 is larger than that in Run 2. This fact is attributed to intensification of the sea ice divergence at the offshore peak because of the amplified wind (Figure 11). $M_{B C}$ is a few times as much as $M_{B o}$ in every experiment, and the increase of $M_{B C}$ by the amplified wind is also larger than that of $M_{B o}$. The increase of the DSW formation rate, nonetheless, is mainly attributed to the volume increase of the offshore DSW (see the March row in Figure 8).

[34] The annual ice production in the Okhotsk Sea is $11.5 \times$ $10^{11} \mathrm{~m}^{3}$ in Run 5 . The annual sea ice production increases by $2.6 \times 10^{11} \mathrm{~m}^{3}$ by the amplified wind (see Table 5), and more than $80 \%$ of this increase is accounted for by the intensification of sea ice divergence due to the amplified wind stress only. The distribution of the annual sea ice production in Run 5 is also similar to that in Run 3.

[35] The sensitivity to coastal ice production by the amplified wind was not seen in the model of Matsuda et al. [2009] probably due to its coarse horizontal resolution as mentioned in section 1 . The horizontal resolution of several kilometers is needed to sufficiently resolve the coastal polynya and properly demonstrate the sensitivity of brine rejection to the wind strength on the northwestern coast.

[36] Figure 13 shows the DSW formation rate in each experiment as a function of density. The formation rate in each density bin is here defined as the difference between the volumes of the redefined DSW within the density bin at the end of the ice period and just before the ice period. The

Table 9. Mass of Salt in the Northern Shelf That Originates From Brine Rejection in the Coastal Region $M_{B C}$ and in the Offshore Region $M_{B o}$ in March

\begin{tabular}{lcc}
\hline Case & $M_{B c}\left(10^{12} \mathrm{~kg}\right)$ & $M_{B o}\left(10^{12} \mathrm{~kg}\right)$ \\
\hline Run 1 & 3.06 & 1.23 \\
Run 2 & 3.00 & 1.19 \\
Run 3 & 3.57 & 1.40 \\
Run 4 & 3.46 & 1.45 \\
\hline
\end{tabular}

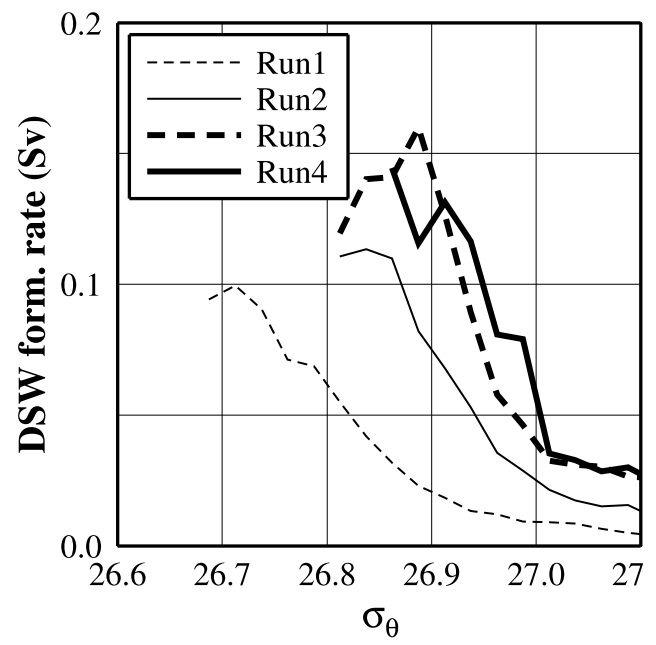

Figure 13. Formation rate of redefined DSW for every $0.025 \sigma_{\theta}$ bin in each experiment.

DSW formation rate is at a maximum around the density threshold used to define DSW (see Table 7) in every experiment. The density at which the DSW formation rate is at a maximum shifts toward the higher side as a result of the tidal mixing around the Kuril Straits, from 26.700 $26.725 \sigma_{\theta}$ in Run 1 to $26.825-26.850 \sigma_{\theta}$ in Run 2. The increase of the DSW formation rate by the tidal mixing effect is relatively small. Thus, the tidal mixing effect mainly makes DSW denser. Figure 14 shows distributions of salinity in the upper layer in November, which is just prior to the ice period. The salinity in the upper layer increases in most of the Okhotsk Sea by the tidal mixing effect in November (Figures 14a and 14b). The averaged salinity in the northern shelf region also increases by 0.13 psu in November (Table 6). Such increase of salinity in the northern region corresponds to the preconditioning of salinity suggested by Nakamura et al. [2006]. The density threshold of DSW in this study changes by the tidal mixing effect. This change is due to the increase of salinity (density) in the northern shelf region prior to the ice period. DSW, defined as the water directly influenced by brine, becomes denser by the preconditioning due to the tidal mixing effect around the Kuril Islands.

[37] The DSW formation rate in Run 3 is larger than that in Run 2 in every density range. It is due to the increase of the DSW formation by the amplified wind as mentioned above. The peak density of the DSW formation moves from 26.825-26.850 $\sigma_{\theta}$ in Run 2 to 26.875-26.900 $\sigma_{\theta}$ in Run 3, thus, the amplification of wind also has an effect of increasing DSW density. There is little increase of salinity in the upper layer of the northern shelf in November by the amplification of wind (Table 6), and the density threshold does not change. The upper layer water saltier than $33.2 \mathrm{psu}$ is found in the offshore region of the northern shelf to the west of $151^{\circ} \mathrm{E}$ in Run 3 (Figure 14c), while it is not found in the northern shelf region but in the southeastern part of the Okhotsk Sea in Run 2 (Figure 14b). The amplified wind intensifies the wind-driven circulation in the Okhotsk Sea, enhances the transport of the tidally induced positive salinity anomaly to the north, and makes the water in the northern shelf region saltier (denser) in November, as suggested by Matsuda et al. [2009]. The consequent higher salinity in the 

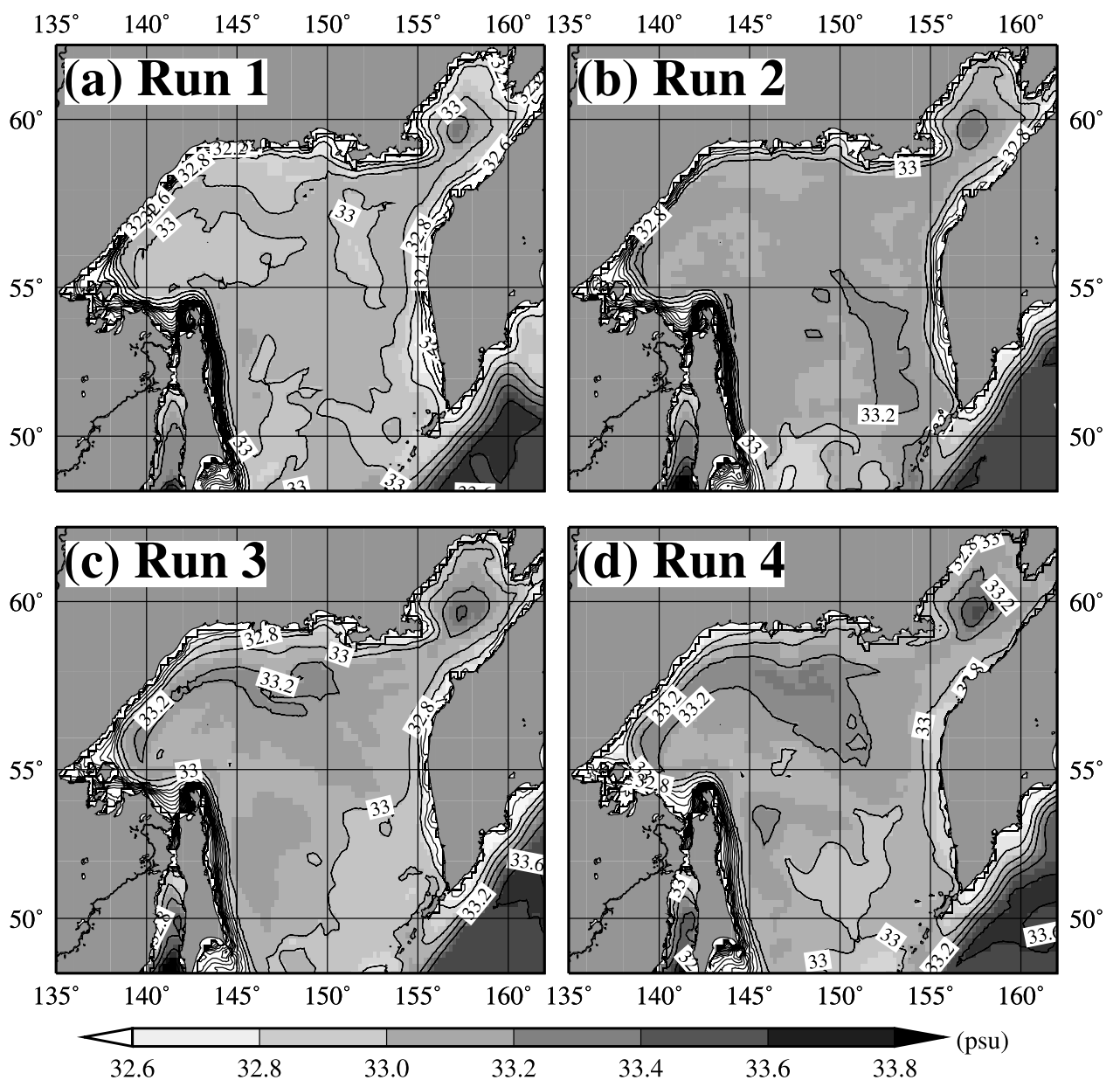

Figure 14. Horizontal distributions of salinity vertically averaged from surface to $100 \mathrm{~m}$ depth in November simulated in (a) Run 1, (b) Run 2, (c) Run 3, and (d) Run 4 (contour interval is 0.2 psu).

offshore region is another precondition to the increase of the volume of offshore DSW.

[38] The DSW formation rate in Run 4 is larger than that in Run 3 at most of the density ranges larger than $26.900 \sigma_{\theta}$, although the peak density of the DSW formation in Run 4 is slightly smaller than that in Run 3. As in the case of the tidal mixing, the reduction of river runoff mainly makes DSW denser. In Run 4, the low-salinity water along the northwestern coast vanishes (Figure 14d), which is the reason for the increase of DSW density. As mentioned in section 2.2, the total river runoff in the Okhotsk Sea is currently not clear, except for the Amur River. This result shows a high dependence of DSW density on the unclarity of river runoff in the Okhotsk Sea.

\section{Summary and Conclusion}

[39] In this study, we investigate the sensitivity of DSW formation in the Okhotsk Sea to the tidal mixing effect around the Kuril Straits, amplified wind, and removal of river runoff in the Okhotsk Sea, except for the Amur, using an ice-ocean coupled model,which well resolves the coastal polynyas in the Okhotsk Sea. DSW formation rate in the Okhotsk Sea is first evaluated with the fixed density and temperature thresholds of Itoh et al. [2003]. The formation rate is larger than those in previous numerical modeling studies and close to the estimate of Itoh et al. [2003] by virtue of the improved sea ice production in the Okhotsk Sea, although the model in this study tends to form too dense water in the northern shelf region. DSW is also found in the offshore region of the northern shelf in this model, whose existence has not explicitly been pointed out but is supported by observations.

[40] DSW is redefined independently for each experiment such that it extracts the water influenced by brine in every experiment. By introducing such new definition the sensitivity of the DSW formation is assessed separately for change of density and of formation rate (Table 7 and Figure 13). Density of DSW changes due to the preconditioning of salinity (density) in the northern part of the Okhotsk Sea prior to the ice period. The tidal mixing around the Kuril Straits and the uncertainty in river runoff considerably affects DSW density but not its formation rate. DSW formation rate increases by the amplified wind due mainly to the increase of volume of offshore DSW. It is achieved by the intensification of sea ice production around the offshore ridge due to intensification of the sea ice divergence and by the increase of salinity in the offshore region of the northern shelf prior to the ice period due to the enhanced transport of the high-salinity water, as suggested by Matsuda et al. [2009]. The sea ice production along the northwestern coast also increases by the amplified wind stress, and it also 
Table 10. Annual Mean Volume and Temperature of the Water With Density Within 26.8-27.0 $\sigma_{\theta}$ and Temperature Within $0.5-1.0^{\circ} \mathrm{C}$

\begin{tabular}{lcc}
\hline Case & Volume $\left(10^{14} \mathrm{~m}^{3}\right)$ & Temperature $\left({ }^{\circ} \mathrm{C}\right)$ \\
\hline Run 2 & 1.24 & 0.89 \\
Run 3 & 2.14 & 0.83 \\
\hline
\end{tabular}

contributes to the increase of DSW formation rate. The amount of salt originating from brine in the coastal region is a few times as much as that from the offshore region in every experiment. It is considered that the increase of brine along the northwestern coast also substantially contributes to the increase of volume of cold dense water through entrainment around the continental slope of Sakhalin, which is located in the downstream region of the northern shelf.

[41] The sensitivity of sea ice production to wind stress along the northwestern coast has not been discussed in previous modeling studies. The horizontal resolution of several kilometers is needed in the northern region to sufficiently resolve the coastal polynya and its sensitivity to wind strength. Water volume in the Okhotsk Sea exhibits a peak in the density range of 26.8-27.0 $\sigma_{\theta}$ and temperature range of $0.5-1.0^{\circ} \mathrm{C}$, which exists around the layer of minimum potential vorticity in the modeled Okhotsk Sea in every experiment (Figure 7). This water qualitatively corresponds to OSMW, which is the source water of NPIW. The simulated OSMW substantially increases and becomes slightly colder by the amplified wind (Table 10). This change in OSMW is achieved through the increase of DSW formation. Such an effect of the wind stress should affect the strength of the intermediate circulation in the North Pacific. This issue will be dealt with in a future paper. The magnitude of wind difference among the sensitivity experiments corresponds to the typical range of interannual wind variation. Therefore, the difference in DSW formation rate due to the change of wind is likely to represent a typical range of its interannual variability.

[42] Acknowledgments. This study is supported by JST/CREST. The authors thank H. Mitsudera, K. I. Ohshima, and S. Nihashi for useful discussions. The topography data around the Kashevarov Bank were provided by K. I. Ohshima. The figures in this paper were produced by the Generic Mapping Tools.

\section{References}

Alfultis, M. A., and S. Martin (1987), Satellite passive microwave studies of the Sea of Okhotsk ice cover and its relation to oceanic processes, J. Geophys. Res., 92(C12), 13,013-13,028.

Gladyshev, S., S. Martin, S. Riser, and A. Figurkin (2000), Dense water production on the northern Okhotsk shelves: Comparison of ship-based spring-summer observations for 1996 and 1997 with satellite observations, J. Geophys. Res., 105(C11), 13,013-13,028.

Griffies, S. M., and R. W. Hallberg (2000), Biharmonic friction with a Smagorinsky-like viscosity for use in large-scale eddy-permitting ocean models, Mon. Weather Rev., 128(8), 2935-2946.

Hasumi, H. (2006), CCSR Ocean Component Model (COCO) version 4.0, Tech. Rep. 25, Cent. for Clim. Syst. Res., Univ. of Tokyo, Chiba, Japan.

Hasumi, H., and N. Suginohara (1999), Sensitivity of a global ocean general circulation model to tracer advection schemes, J. Phys. Oceanogr., 29(10), 2730-2740.

Hunke, E. C., and J. K. Dukowicz (1997), An elastic-viscous-plastic model for sea ice dynamics, J. Phys. Oceanogr., 27(9), 1849-1867.
Ishizaki, H., and T. Motoi (1999), Reevaluation of the Takano-Oonishi scheme for momentum advection on bottom relief in ocean models, J. Atmos. Oceanic Technol., 16(12), 1994-2010.

Itoh, M., K. I. Ohshima, and M. Wakatsuchi (2003), Distribution and formation of Okhotsk Sea Intermediate Water: An analysis of isopycnal climatological data, J. Geophys. Res., 108(C8), 3258, doi:10.1029/ 2002JC001590.

Kalnay, E., et al. (1996), The NCEP/NCAR 40-year reanalysis project, Bull. Am. Meteorol. Soc., 77(3), 437-471.

Kara, A. B., P. A. Rochford, and H. E. Hurlburt (2000), Efficient and accurate bulk parameterizations of air-sea fluxes for use in general circulation models, J. Atmos. Oceanic Technol., 17(10), 1421-1438.

Kitani, K. (1973), An Oceanographic Study of the Okhotsk Sea, vol. 9, pp. 45-77, Far Seas Fish. Res. Lab., Orido, Japan.

Kowalik, Z., and I. Polyakov (1998), Tides in the Sea of Okhotsk, J. Phys. Oceanogr., 28(7), 1389-1409.

Leonard, B. P., M. K. Macvean, and A. P. Lock (1993), Positivity-preserving numerical schemes for multidimensional advection, NASA Tech. Memo. 106055/ICOMP-93-05, 62 pp., Natl. Aeronaut. and Space Admin. Washington, D. C.

Martin, S., R. Drucker, and K. Yamashita (1998), The production of ice and dense shelf water in the Okhotsk Sea polynyas, J. Geophys. Res., 103(C12), 27,771-27,782.

Matsuda, J., H. Mitsudera, T. Nakamura, K. Uchimoto, T. Nakanowatari, and N. Ebuchi (2009), Wind and buoyancy driven intermediate-layer overturning in the Sea of Okhotsk, Deep Sea Res. Part I, 56, 1401-1418.

Mellor, G. L., and T. Yamada (1982), Development of a turbulence closure model for geophysical fluid problems, Rev. Geophys., 20(4), 851-875.

Mizuta, G., Y. Fukamachi, K. I. Ohshima, and M. Wakatsuchi (2003), Structure and seasonal variability of the East Sakhalin Current, J. Phys. Oceanogr., 33(11), 2430-2445.

Nakamura, T., and T. Awaji (2004), Tidally induced diapycnal mixing in the Kuril Straits and its role in water transformation and transport: A three-dimensional nonhydrostatic model experiment, J. Geophys. Res., 109, C09S07, doi:10.1029/2003JC001850.

Nakamura, T., T. Awaji, T. Hatayama, K. Akitomo, T. Takizawa, T. Kono, Y. Kawasaki, and M. Fukasawa (2000), The generation of large-amplitude unsteady lee waves by subinertial $\mathrm{k}_{1}$ tidal flow: A possible vertical mixing mechanism in the Kuril Straits, J. Phys. Oceanogr., 30(7), 1601-1621.

Nakamura, T., T. Toyoda, Y. Ishikawa, and T. Awaji (2006), Enhanced ventilation in the Okhotsk Sea through tidal mixing at the Kuril Straits, Deep Sea Res. Part I, 53, 425-448.

National Geophysical Data Center (1988), Digital relief of the surface of the Earth, http://www.ngdc.noaa.gov/mgg/global/etopo5.HTML, Natl. Oceanic and Atmos. Admin., Boulder, Colo.

Nihashi, S., K. I. Ohshima, T. Tamura, Y. Fukamachi, and S. Saitoh (2009), Thickness and production of sea ice in the Okhotsk Sea coastal polynyas from AMSR-E, J. Geophys. Res., 114, C10025, doi:10.1029/ 2008JC005222.

Noh, Y., and H. J. Kim (1999), Simulations of temperature and turbulence structure of the oceanic boundary layer with the improved near-surface process, J. Geophys. Res., 104(C7), 15,621-15,634.

Ogi, M., Y. Tachibana, F. Nishio, and M. A. Danchenkov (2001), Does the fresh water supply from the Amur River flowing into the Sea of Okhotsk affect sea ice formation?, J. Meteorol. Soc. Jpn., 79(1), 123-129.

Ohshima, K. I., M. Wakatsuchi, Y. Fukamachi, and G. Mizuta (2002), Near-surface circulation and tidal currents of the Okhotsk Sea observed with satellite-tracked drifters, J. Geophys. Res., 107(C11), 3195, doi:10.1029/2001JC001005.

Ohshima, K. I., T. Watanabe, and S. Nihashi (2003), Surface heat budget of the Sea of Okhotsk during 1987-2001 and the role of sea ice on it, J. Meteorol. Soc. Jpn., 81(4), 653-677.

Ohshima, K. I., D. Simizu, M. Itoh, G. Mizuta, Y. Fukamachi, S. C. Riser, and M. Wakatsuchi (2004), Sverdrup balance and the cyclonic gyre in the Sea of Okhotsk, J. Phys. Oceanogr., 34(2), 513-525.

Ono, J., K. I. Ohshima, G. Mizuta, Y. Fukamachi, and M. Wakatsuchi (2006), Amplification of diurnal tides over Kashevarov Bank in the Sea of Okhotsk and its impact on water mixing and sea ice, Deep Sea Res. Part I, 53, 409-424.

Perry, G., P. Duffy, and N. Miller (1996), An extended data set of river discharges for validation of general circulation models, J. Geophys. Res., 101(D16), 21,339-21,349.

Röske, F. (2001), An atlas of surface fluxes based on the ECMWF reanalysis: A climatological dataset to force global ocean general circulation models, MPI Rep. 323, Max-Planck-Inst. für Meteorol., Hamburg, Germany.

Semtner, A. J. (1976), A model for the thermodynamic growth of sea sce in numerical investigations of climate, J. Phys. Oceanogr., 6(3), 379-389. 
Shcherbina, A. Y., L. D. Talley, and D. L. Rudnick (2003), Direct observations of North Pacific ventilation: Brine rejection in the Okhotsk Sea, Science, 302, 1952-1955.

Shcherbina, A. Y., L. D. Talley, and D. L. Rudnick (2004a), Dense water formation on the northwestern shelf of the Okhotsk Sea: 1. Direct observations of brine rejection, J. Geophys. Res., 109, C09S08, doi:10.1029/ 2003JC002196.

Shcherbina, A. Y., L. D. Talley, and D. L. Rudnick (2004b), Dense water formation on the northwestern shelf of the Okhotsk Sea: 2. Quantifying the transports, J. Geophys. Res., 109, C09S09, doi:10.1029/ 2003JC002197.

Simizu, D., and K. I. Ohshima (2002), Barotropic response of the Sea of Okhotsk to wind forcing, J. Oceanogr., 58(6), 851-860.

Simizu, D., and K. I. Ohshima (2006), A model simulation on the circulation in the Sea of Okhotsk and the East Sakhalin Current, J. Geophys. Res., 111, C05016, doi:10.1029/2005JC002980.

Smagorinsky, J. (1963), General circulation experiments with the primitive equations, Mon. Weather Rev., 91(3), 99-164.

Steele, M., R. Morley, and W. Ermold (2001), PHC: A global ocean hydrography with a high-quality Arctic Ocean, J. Clim., 14(9), 2079-2087.
Takizawa, T. (1982), Characteristics of the Soya Warm Current in the Okhotsk Sea, J. Oceanogr. Soc. Jpn., 38, 281-292.

Talley, L. (1991), An Okhotsk Sea water anomaly: Implications for ventilation in the North Pacific, Deep Sea Res. Part A, 38, suppl. 1, S171-S190.

Tsujino, H., H. Hasumi, and N. Suginohara (2000), Deep Pacific circulation controlled by vertical diffusivity at the lower thermocline depths, J. Phys. Oceanogr., 30(11), 2853-2865.

Watanabe, T., and M. Wakatsuchi (1998), Formation of 26.8-26.9 $\sigma_{\theta}$ water in the Kuril Basin of the Sea of Okhotsk as a possible origin of North Pacific Intermediate Water, J. Geophys. Res., 103(C2), 2849-2865.

Yasuda, I. (1997), The origin of the North Pacific Intermediate Water, J. Geophys. Res., 102(C1), 893-909.

H. Hasumi and Y. Sasajima, Atmosphere and Ocean Research Institute University of Tokyo, 5-1-5, Kashiwanoha, Kashiwa, Chiba 277-8568, Japan. (hasumi@aori.u-tokyo.ac.jp; sasajima@aori.u-tokyo.ac.jp)

T. Nakamura, Institute of Low Temperature Science, Hokkaido University, Kita-19, Nishi-8, Kita-ku, Sapporo, Hokkaido 060-0819, Japan. (nakamura@lowtem.hokudai.ac.jp) 